\title{
El poder de lo sagrado, el fundamento de la construcción regional
}

Recibido: 15.05 .18

Aprobado: 21.09.18
Susana Aldana Rivera

Pontificia Universidad Católica del Perú saldanarivera@gmail.com

\section{RESUMEN}

El interés de este artículo es la de reflexionar sobre la vitalidad histórica de un particular espacio de frontera, entre Loja y Huancabamba, ubicado en el confín de dos estados nacionales con una sierra poblacionalmente bastante blanca, con pocos indios, casi sin criollos y con una frontera caracterizada diferente por cuanto es traslucida por su movimiento simbólico sacro. Reflexiona sobre la conversión de un espacio sagrado en un espacio económico, de explotación y uso en función de los intereses del reino, parte del imperio español. Analiza en cómo el límite ya establecido y asumido localmente sufre las presiones del comercio, humanamente establecido por vínculos de muy larga data, y los cambios socio-económicos que preparan el camino a la república.

Palabras Clave: Piura; Loja; región; espacio de frontera; Huancabamba; república.

\section{The power of sacred, basis of regional construction}

\begin{abstract}
This article aims to reflect on historical vitality of a particular frontier area, between Loja and Huancabamba, two national states with a quite white population, with few Indians, almost without Creoles, with a border characterized different because it is translucent by its sacral symbolic movement. We reflects on the conversion of a sacred space into an economic space, its exploitation and use in accordance with kingdom interests, part of the Spanish empire. It analyzes how limits are already established and assumed, locally suffers from the pressures of trade, that were humanly established by long-standing ties and socio-economic changes that prepare the way to the republic.
\end{abstract}

KeYwords: Piura; Loja; región; frontier area; Huancabamba; república. 
H oy en día, la región emerge, la nación se difumina. No desaparece sino que pierde su importancia monopólica en cuanto forma de ordenamiento de las sociedades por cuanto se está enfrentando una nueva construcción sociopolítica, la gobernanza global. Por ello, surgen y resurgen espacios diferentes que formaron parte de las construcciones nacionales aunque, por lo menos en el caso del Perú, quedaron ocultas ante la fuerza del proceso creador de las formas políticas republicanas: desde la creación del estado, se convirtió en prioritario, la construcción de una burocracia estatal (estado) y centralizar y controlar los territorios de estos nuevas repúblicas; las tierras suponían materias primas y variados recursos, riqueza, fundamento y posibilidades de la explotación industrial y por tanto, del bien material de la sociedad a través de su inclusión en el naciente y creciente mercado internacional.

Las regiones emergieron en este momento en paralelo a la creación burocrática estatal y a la inserción en un sistema liberal industrial y capitalista porque bebían en una existencia muy profunda en el tiempo. Los nuevos límites republicanos cortaron y modificaron los espacios tradicionales vinculados desde por lo menos mil años sino más; la frontera, ese rango humano en un territorio dado ${ }^{1}$, se convirtió en límite y como era necesario, fortalecer el corazón capitalino del nuevo ordenamiento, fue invisibilizada muy rápidamente, fuera por su lejanía, por la incapacidad de entender la cultura, la dificultad de acceso geográfico o simplemente la urgencia de un sinfín de situaciones nacionales. Así muchas regiones simplemente se vieron cortadas y cooptadas en su proceso de vida por los estados nacionales que reorientaron centrípetamente los intereses del estado y que buscaron quebrar los vínculos fuera de los límites nacionales. El proceso fue muy interesante pero con éxito relativo pues hoy estos espacios se reinventan a partir del contacto con espacios externos a ellos e identitariamente, rescatan y reformulan elementos culturales que se hunden en la noche de los tiempos. Esta re-etnización recupera vínculos y relaciones humano-territoriales que supe-

1 El trabajo clásico de Turner (1986) recupera el proceso de expansión y explayamiento económico de los pioneros norteamericano en las tierras del oeste de este país. Para ello, establece la diferencia entre frontera, como un rango humano movible en concordancia con el interés y la necesidad humana, y el límite, construido y arcifinio, que recupera el estado o la burocracia política. ran los límites tan cuidadosamente construidos por los estados nacionales.

En la medida que estas regiones suponen la recuperación de visiones y formas de vida que subrepticiamente se mantuvieron vigentes en el marco nacional-liberal-industrial, también resurge un corpus de ideas que remite, más que al pasado, a las percepciones recreadas del pasado en las que el territorio, por ejemplo, deja de ser un espacio plano de explotación humana sino que recupera una vitalidad sagrada que, como se ha dicho, quedó oculta ante las nuevas formas del sistema. La transversal o depresión de Huancabamba es un espacio que cumple con lo dicho, un eje comunicante que va de esta cuenca hacia Ayabaca donde comienza una suerte de pequeñas microcuencas que cierran hacia Loja y clausuran hacia Cuenca. Es un espacio muy particular que, además de fungir de frontera geográfica entre Andes septentrionales y centrales; de límites entre dos países como Perú y Ecuador, desenvuelve todo una suerte de representaciones simbólicas fundadas en tradiciones míticas-religiosas plenamente vigentes, inventadas y reinventadas, que se enmarcan en un espacio y mentalidad glocal. ${ }^{2}$ Huancambamba es un espacio muy visitado por sus lagunas curanderas $^{3}$; la gente después de florecerse ponen en agenda visitar, en la cuenca siguiente, al Señor Cautivo de Ayabaca y de allí, caminar fervorosa y vitalmente a la Señora del Cisne en Loja o bajar en gran caminata hasta Mercedes en Paita. Y no falta quien se instala en Vilcabamba (Loja) en busca de la eterna juventud o siguiendo el impacto de la espiritualidad New Age. Reemerge el concepto de lo sagrado que jamás fue desplazado ni por la religión cristiana ni por las ideologías políticas.

2 Glocalidad es un término que se refiere a la localidad en relación con lo global y la globalización y los posmercados o relaciones económicas que se generan entre las organizaciones globales, como transnacionales y multinacionales, directamente con el espacio local pasando muchas veces por encima de lo nacional. La frase que articula la perspectiva es «piensa en global, actúa en local». Ver por ejemplo la reseña al libro de Rifkin que hace María de Lourdes Ortiz Boza (2010).- «Glocalidad y posmercado: ¿sellos de la sociedad del siglo xxi? Jeremy Rifkin (2004), El fin del trabajo. Nuevas tecnologías contra puestos de trabajo. El nacimiento de una nueva era.- Barcelona, Paidós.- En: Contribuciones desde Coatepec 121. Número 19, juliodiciembre 2010. Allí podremos avistar las complejidades que suponen estas categorías.

3 El turismo médico es tan fuerte que hay varias compañías de turismo dedicadas solo al rubro. Ver por ejemplo y entre otras, http://www. huaringastravel.com/, o el blog http://wwwhuaringastravel.blogspot. pel. 
El interés de este artículo es reflexionar sobre la vitalidad histórica de este particular espacio de frontera, ubicado en el confin de dos estados nacionales con una sierra poblacionalmente bastante blanca con pocos indios - que hay-y sin propiamente criollos y con una frontera caracterizada diferente por cuanto es traslucida por su movimiento simbólico sacro. No solo frontera móvil, siguiendo a Turner (1986) como se ha dicho, sino también percibiendo su apertura hacia las formas simbólicas del concepto: el límite entre el nosotros y los otros que responde a una percepción -falsa desde lo local, real desde lo nacionalde ser espacios vacíos de civilización pero plenos de naturaleza. Betancourt y Gonzáles (2015) realzan lo permeable, lo poroso y lo flexible de la realidad geográfica de una frontera y que en este caso, se aplica al eje Loja-Huancabamba, primero como frontera natural entre los Andes septentrionales y los centrales que se construye como una "llave del reino" para la etapa prehispánica que permitió «cerrar» el rico espacio centroandino a culturas y grupos no deseados provenientes de la selva: los seńores establecen una zona de control geográfico pero también militar y sobre todo, ¿sagrado?

En esta línea y como segundo acápite, reflexiona sobre la conversión de un espacio sagrado en un espacio económico, de explotación y uso en función de los intereses del reino, parte del imperio español. Analizar cómo la construcción del límite español, línea de separación entre mapas y audiencias, diluye la importancia de este espacio y lo convierte en una frontera, alejada, de la audiencia y del virreino: lo importante es el oro y la plata, de muy difícil extracción desde las nada civilizadas selvas del sur del Ecuador y del norte del Perú. La tecnología es el tope y además, el fundamento bullionista del reino teje sus vínculos definitivamente con el sur andino aunque algún espacio de interés habrá para los productos de la tierra.

Finalmente, en un tercer_acápite,_analizamos en cómo el límite ya establecido y asumido localmente sufre las presiones del comercio, humanamente establecido por vínculos de muy larga data, y los cambios socio-económicos que preparan el camino a la república. Para el siglo XviII, la frontera es más política que geográfica, en que se segrega y se separa socialmente a los grupos humanos porque es cada vez más importante la explotación económica de la prácticamente materia prima en función del ordenamiento virreinal. Las percepciones simbólicas se construyen de la mano con la vocación exportadora del virreino pues los indios, actores sociales percibidos como no civilizados, son desplazados por los criollos (costeños y capitalinos), sujetos deseables para la nación. La quinina enviada a la Real Botica de Madrid es quizás uno de los elementos más visible de ese tránsito socio-económico de producto de la tierra a materia prima de un límite alejado - espacio salvaje que debe ser utilizado para un «nosotros», capitalino y estatal. Pero es un nosotros en construcción que tomará plenamente fuerza después, en la república. Mientras tanto los actores de la macroregión surecuatoriananor peruana ${ }^{4}$, logran hacer sentir el peso de las estructuras locales construidas en el olvido del siglo XVII y que se explaya, poderosa, en el siglo XviII.

\section{El espacio en cuestión y sus características}

La transversal o depresión del Huancabamba es un espacio geográfico-social muy particular que se expande entre el sur del Ecuador y el norte del Perú. Un eje que establece no solo un límite republicano sino que geográficamente denota una frontera en que se transita de los Andes septentrionales a los Andes centrales. Una frontera humana, amplia y variable que recién para fines del siglo XviII emergerá readecuada en términos del sistema llegado y desenvuelto por los españoles durante el virreinato del Perú, que para ese momento, comenzaba a orientarse hacia lo económico y visible, por ejemplo, en la demanda de la quinina. Detrás estuvieron los intereses iniciales de construcción del capitalismo y hará que este espacio, desde Cuenca, pasando por Loja y explayándose, desde las serranías piuranas de Ayabaca y Huancambaba, se extienda como límite norte del espacio centro andino con capital en Trujillo. No olvidemos que esta ciudad costeńa se convierte "naturalmente» en la cabeza de esta macroregión; no sólo Chanchan y el conjunto de huacas tuvo importancia en el pasado chimú sino sobre todo, con los españoles, era necesario contar con un puerto para sacar los productos de la sierra. Desde aquí se perfila la vocación exportadora del virreinato, en particular a fines del mismo, y sobre todo de la republicana.

4 Ver mis trabajos sobre la región, Aldana (1991, 2016). 
En ese espacio que me interesa, entre Loja y Piura se forma una suerte garganta que permite un tránsito amable entre ambos Andes. Pero lo interesante de este espacio es que subiendo por las cuencas del Piura y del Chira hacia Huancabamba y Ayabaca y enfilando hacia Loja y Cuenca, se cruza serranías flanqueadas de un lado, por la difícil montańa, húmeda tropical guayaquileña, una suerte de selva occidental ecuatoriana, y del otro, la selva amazónica del oriente ecuatoriano y la selva norperuana. Como lo señala un estudioso local lojano, el Sr. Numa Maldonado 5 el Ecuador es un "país tropandino, de forma trapezoidal, con el lado menor hacia el SO", es decir, que se estrecha hacia la zona fronteriza entre Perú y Ecuador. La Transversal de Huancabamba es la depresión más baja de los Andes y por alli desaguan el Chamaya, el Marañón y el Amazonas y se extiende desde Oña ( $3^{\circ} 30$, LatS) hasta el paso de Porculla $\left(5^{\circ} 30^{\prime} \mathrm{LatS}\right)$ en el tránsito entre Lambayeque y Chiclayo; recibe tal nombre porque en este lugar los Andes bajos cambian bruscamente de dirección, de NE-SO a NO-SE, siguiendo el perfil costanero del Pacífico. La costa sur ecuatoriana capta la humedad periódica de la corriente cálida del Niño y la fluvial del Guayas, Jubones y Arenillas y consta de esteros y manglares, que hacia el sur se convierte en un litoral amplio y desértico, el de Sechura en el norte del Perú, Piura para mayor especificidad y justamente en la zona lojana donde se concentran diferentes pisos ecológicos (tropical, premontano, montano, subalpino y tropical húmedo) que llevan a Maldonado a señalar que es quizás la zona más compacta pero con mayor biodiversidad $40 \%$ - del Ecuador.

En el caso del Perú, estamos ante las serranías de la región de Piura que no puede ser desvinculada de la costa como lo prueba la relación Cautivo de Ayabaca - Mercedes de Paita y las procesiones, de numerosísimos fieles. Es decir, este espacio cuenta con dos ejes de vida constituidos a partir de los dos grandes valles costeños (Chira y Piura) y que dan pie a cuatro habitats (el litoral, los valles, el despoblado costeńo y el espacio serrano). Por cierto que Ayabaca no es igual a Huancambamba por la sierra, pero por lo común, se la asume como una unidad porque se tiene un mismo patrón de asentamiento y de producción

5 Disertación para la incorporación del Sr. Numa Maldonado a la Academia Nacional de Historia el Ecuador, filial Loja. Octubre 2016 que fundamenta una sociedad más homogénea que la costeña. Es decir que la región de Piura está cruzada por dos grandes ríos, Piura y Chira, que forman sendos espacios de vida transversales con valles bastante ricos para sociedades eminentemente agrícolas que son, además, la entrada a una sierra no muy alta pero sumamente cortada, con profundos precipicios y con climas húmedos fríos, con climas de páramo y janquilla; su páramos tiene menos de 20 grados de inclinación y las laderas de los cerros son sumamente abruptas; tienen entre 40 y $70 \%$ de pendiente. Ayabaca está hacia el norte, muy cerca del Ecuador, tiene montañas que alcanzan los $3000 \mathrm{~m}$ s.n.m. y la ciudad está a 2709 m s.n.m. Mientras que por el sur, Huancabamba cuenta con la cumbre más alta (Cerro Negro 3960 m) dando pie al Páramo y río del mismo nombre que, junto con el Quiroz, abren el espacio hídrico más importante de toda la zona norte del Perú: un conjunto de ríos se inician en su entorno y sus famosas lagunas conforman corazón curanderil de la América del Sur; hacia el otro lado, hacia el este, se bajaría a un paisaje de selva alta tropical, cubierto de tupida vegetación arbustiva y arbórea.

Una sierra tan verde que contrasta con la costa y el largo trecho de arenas; finalmente en Piura se explaya la franja desértica más ancha del Perú. Para el norte peruano, el mar es importante y en términos de Piura, es un sexto espacio de vida. Los pescadores de Sechura cuentan con el mar como fuente de aprovisionamiento cotidiano. Además, la corriente de Humboldt, que marca la riqueza ictiológica del litoral peruano, comienza a desviarse hacia el oeste justamente en Piura y marca la realidad regional y nacional con crisis cíclicas hoy conocidas como ENSO (El Niño Southern Oscillation). Situación estrechamente vinculada a las lluvias extremas o sequías fuertes de la sierra en esta transversal de Huancabamba.

Los estudiosos locales son siempre los que más conocen su región como el mencionado Numa Maldonado y Juan Paladines desde Loja. Pero pocos trabajos hay para la sierra piurana; quizás el más renombrado sea el de Miguel Justino Ramírez, sacerdote, con sus acuarelas huancabambinas y de manera contemporánea, Juan Paz y Rudy Mendoza ${ }^{6}$. Pero

6 Para mi, los estudiosos locales son personas que pueden ser profesionales - generalmente profesores_ que aman su región y por tanto, buscan desarrollar su historia como fundamento de ella. No pueden ser historiadores porque no hay esa carrera en las universidades téc- 
son los arqueólogos quienes nos ofrecen información que nos completa el escenario; baste ver los continuos esfuerzos que realizan ${ }^{7}$. Pero en general, poca atención ha concitado este espacio lojano-piurano. Desde Jorge Marcos y sus trabajos sobre Cuenca; Jaime Idrovo y Diego Gonzáles Ojeda desde Loja; Jean Guffroy con sus estudios tanto sobre Loja como sobre la sierra piurana que van de la mano del interés de A.M Hocquenghem y Makowski y su equipo con trabajo sobre Vicús, entre otros ${ }^{8}$.

\section{En el mundo andino prehispánico, una llave del reino}

El clásico estudio de Juan Manuel Zapatero sobre el Caribe en el siglo XviII,el autor utiliza una interesante categoría, «las llaves de las Yndias del Peru». Un concepto que hace referencia a lugares-claves cuya posesión era decisiva política y militarmente para la seguridad y desenvolvimiento de un territorio dado. Eran puntos por donde se "cerraba" el Caribe y se podía detener las incursiones de marinos enemigos y frenar la presencia no deseada de piratas y corsarios en el conjunto americano; comerciantes encubiertos de otras nacionalidades, sobre todos ingleses y franceses, como todos bien sabemos Por tanto, estos puntos estratégicos estaban bien fortificados y contaban con hombres para su protección. Cartagena de Indias, por ejemplo, era la llave del reino del Perú (Zapatero 1964: 7).

nicas locales. Sus trabajos son sumamente serios y con fundado conocimiento factual pero siempre tienen un matiz de amoroso orgullo sobre su tierra. El Sr. Moya (1994) era un interesante ejemplo de ello; un periodista cuyos escritos dieron por primera vez un pasado coherente a Piura. Hoy Juan Paz y Ruddy Mendoza hacen lo mismo. Desde Loja, tuve la suerte de conocer al Sr. Numa Maldonado y el Sr. Juan Paladines quien me comentaron sobre la historia de la región.

7 En 2010 hubo una reunión de arqueólogos peruanos y ecuatorianos. Ver la publicación, coordinada por Hans Mejía Guerrero, I Encuentro de arqueólogos del norte del Perú y el sur del Ecuador: Memorias. Relaciones regionales y perspectivas de futuro. Cuenca: Universidad de Cuenca; Gobierno Provincial del Azuay. Recuperada de http://es.slideshare.net/mobile/hansmejia/i-encuentro-de-arquelogos-del-norte-del-per-y-el-sur-del-ecuador-memorias. Allí se encuentran los trabajos de arqueólogos sobre Cuenca, Idrovo y Ferández y sobre Lambayeque, Carlos Wester.

8 Sobre el norte del Perú, ver por ejemplo, Jean Guffroy, Peter Kaulicke y Krzysztof Makowski (1989).- «La Prehistoria del departamento de Piura: estado de los conocimientos y problemática» (Bulletin de l'Institut Francais d'Etudes Andines, No. 2, pp.117-142) y el segundo, de Anne Marie Hocquenghem (1991), «Frontera entre «áreas culturales» nor y centroandinas en los valles y la costa del extremo norte peruano" (Bulletin de l'Institut Francais d'Etudes Andines, 20(2): 309-348).
No es una teoría que refleje las complejidades contemporáneas pero quizás si las pasadas. Puede suponerse que en toda sociedad, sea española o no, cuya riqueza se fundaba en la producción agrícola y en la circulación de esos productos debió haber habido espacios-llaves del reino o puntos estratégicos de control clave que de algún modo resultaban importantes para la realización social de un grupo humano dado. El control de estos puntos aseguraba la riqueza de ese espacio, tal como fuera entendido el término, puesto que al ser estratégico era buscada de realizarse de manera exclusiva y excluyente a un grupo dado y no a otros. Pienso en el espacio que me interesa es uno de ellos.

A lo largo y ancho de esta zona de frontera, nos encontramos con grupos étnicos que, al parecer, no fueron nunca del todo incorporadas a una forma supra local de organización política. Como señala Guffroy y González Ojeda ${ }^{9}$, hay una ruptura cultural importante en la provincia de Loja entre los siglos VII y XI de nuestra era con la llegada de grupos de población oriundos de la Amazonía, pertenecientes a la familia lingüística Jíbaro. Grupos hasta con seis variedades lingüísticas que ya estaban asentados en esta zona de Loja para cuando llegaron los incas hacia 1470. Al parecer, irrumpieron desde la selva y se establecieron por la zona: Paltas, en la parte central y norte de la provincia; los Calvas, hacia el sur; los Malacatos en el este y los Bracamoros en la vertiente oriental de la cordillera. Además estaban los indios cańaris, establecidos en Cuenca pero también en la zona serrana de Lambayeque, donde hasta hoy se les encuentra, entre Incahuasi y Ferreñafe.

No deja de ser interesante preguntarse el por qué en esta Transversal de Huancabamba que cierra hacia Cuenca, fuera del espacio andino central pero la frontera del mismo, nunca se generó un reino o imperio abarcante de los diferentes conjuntos humanos; una investigación más profunda en los libros ecuatorianos probablemente nos daría la respuesta. Pero es ciertamente una característica de los Andes septentrionales; en Ecuador se habla siempre de la Confederación Shyris que supone grupos autónomos pero cohesionados y organizados de manera diferente a lo que podía ser un reino al estilo Chimú, que se

9 Diego González Ojeda URL: www.utpl.edu.ec/arterupestre En Rupestreweb, http://www.rupestreweb. info/ 2008 
explayaba sobre un territorio de mil kilómetros (32 valles de la costa norte peruana) o un imperio como el inca que traspasó las fronteras del espacio andino central y las llevó hasta la hoy Colombia sino más y hacia el sur, hasta Chile; casi un millón de kilómetros cuadrados y un vasto conjunto de grupos humanos. ¿O en realidad se estaría ante confederaciones más que continuidades imperiales al estilo europeo?

En todo caso y desde muy temprano si fue común la presencia de momentos de nucleación política en el espacio centroandino; momentos en que un grupo humano colocaba a otros bajo su impronta religiosa, militar, cultural. Son llamados horizontes por los arqueólogos porque inicialmente fueron controles socio-políticos indirectos y en términos religiosos. Así Chavín se expandió desde su capital religiosa en Chavín de Huantar y generó varios núcleos en territorios tan lejanos como por ejemplo, Piura. La base del poder chavín fue la creación de un calendario agrícola que, de un lado, comunicaba a los dioses con los hombres y del otro y de algún modo, debió asegurar la riqueza agrícola. A lo largo de casi mil años (1000 a. C.- 200 d. C.), la influencia de esta cultura se dejó sentir por todo el espacio que hoy se reconoce como el centro del Perú. Y la pregunta es si esas lejanas colonias en Piura no tenían nada que ver con la Depresión y la Transversal de Huancabamba, con esta zona de frontera entre los Andes centrales y septentrionales y la necesidad de tener presencia en ella.

Si bien y como se afirma, esta cultura tuvo una influencia netamente religiosa, fue Wari el imperio que se expandió sobre el corazón del espacio centroandina (600-900 d. C.); un pueblo que diferenció lo civil de lo religioso, que le dio a la guerra una gran importancia económica y social y que comenzó a tejer una tupida red de poblados que fueron centros de producción de textiles, cerámica, metalurgia y otras artesanías. Pero que también sabemos, tuvo algún tipo de vinculación eminentemente religiosa Tiahuanaco. ¿Por qué Piura le resultaba un espacio interesante? Se sabe que los wari llegan hasta la zona; Cabello de Balboa señalaba que la migración de grupos de la sierra a la costa había sido impulsada por la llegada de este grupo $^{10}$.

10 Es para este momento, cuando se registran los mitos en torno a la llegada de Naylamp y Tacaynamo. Cabello de Balboa es la fuente principal de todo lo que se conoce. Pero el tema aún espera un buen estudio. Historias generales de Piura nos ofrecen un panorama gene-
Hocqueghem (1991) propone que desde muy temprano, el interés del espacio centroandino ha sido controlar esta zona frontera tránsito hacia el espacio Andino septentrional; una llave clave que permitía cerrar, proteger, controlar quien entraba y quien salía de un espacio agrícolamente tan rico como el espacio centroandino. Quizás los grupos protojíbaros - como los denomina Guffroy- nunca fueron del todo integrados y por eso hubo una suerte de conflicto permanente en la zona. Porque con la selva, se sabe, que no hay mayor interés por incorporarla al territorio centroandino; se la utiliza para el intercambio pero no para la expansión ni la asimilación. Quizás, como se señalan los etnohistoriadores peruanos ${ }^{11}$, para una sociedad agrícola, las tierras selváticas resultan poco atractivas por la poca capa de tierra utilizable que tienen; por las lluvias que inundan y lavan esa pequeña tierra además de grupos étnicos sumamente belicosos y muy difíciles de atraer hacia las formas más organizadas de vida ubicadas en la sierra.

¿Cuál era la relación de estas serranías con la costa? Finalmente hasta hoy, el único punto de salida para Loja es Paita; la estructura nacional ha facilitado la carretera a Guayaquil y a Machala pero la geográficamente directa es con la costa piurana. Pero poco se sabe de la relación costa-sierra en el norte peruano. Esta sierra norteña tiene grupos humanos más bien belicoso y no se sabe, por ejemplo, cual fue la relación de los Chimús con estos grupos de sierra. Supuestamente este reino del Chimor (s. XIII d. C.) se explayó por la costa y mantenía relaciones de intercambio y contactos con la sierra; por ejemplo, con los Cajamarcas. Pero ¿cómo se dio dicha expansión? Se puede deducir que enfrentaron y conquistaron a los tallanes o piuranos de época; este grupo negoció con los incas para poder liberarse de los chimús. Por tanto, fueron conquistados, no asimilados. Y cuando llegaron los españoles, se sabe que estos caciques cajamarquinos fueron los primeros señores indios en

ral de toda esta etapa prehispánica. Ver Moya (1994), Aldana y Diez () y también Del Busto (2004)

11 Pienso en las afirmaciones de F.Pease en sus clases sobre etnohistoria y sobre el Tawantinsuyu. Ver los clásicos trabajos de este etnohistoriador y también los de M.Rostowrowski. Como por ejemplo, Pease G. Y., Franklin (2001).- Del Tahuantinsuyo a la historia del Perú.- Lima: PUCP, 39 p. Y de Rostowrowski, María (2014).- Obras completas.Lima: IEP. 
establecer solar en terminos de la ciudad de Trujillo en los linderos de Chanchan ${ }^{12}$.

Sabemos que la ventaja de las sociedades de sierra es que controlan las cabeceras de las cuencas y con ello la vida y la producción de todo los valles: Ríos y riachuelos, lagunas y jagueyes son claves para la reproducción agrícola. Y estamos hablando de un complejo sistema hídrico en esta Transversal de Huancabamba que explaya lagunas desde Ayabaca hasta Huancambaba mismo y cuenta con ese pequeño conjunto de ríos que caracteriza las microcuencas lojanas. ¿Qué tipo de incidencia tiene todo este sistema en el medioambiente de la sierra norte. Por ejemplo, poco o nada se sabe de las Lagunas de Huancabamba. ¿Son curanderas por el tipo de agua que tienen; son mineralizadas? O son sagradas porque de alguna manera se las reconoce como claves dentro de todo el sistema hídrico del norte peruano. No se han hecho mayores estudios sobre el tema ${ }^{13} \mathrm{Y}$ claro está que el acceso o es por el Catamayo-Chira o, mucho más escabroso, el Puyango-Tumbes.

Para el sur, si se sabe la importancia de un lago como el Titicaca en la meseta surandina: al temperar el ambiente, se posibilita la agricultura y sobre todo, la ganadería; Lupaqas y Pacajes contaban con grandes manadas de vicuñas, alpacas y llamas entre los 3000 y 4000 m s.n.m. Y por cierto que Mamacha Copacabana es una de las Vírgenes más respetadas del espacio circumlacustre Titicaca; la fertilidad es la marca principal del culto. ¿Será que esta Transversal de Huancabamba cumple un rol semejante? ¿Será que este conjunto de lagunas y micro-micro cuencas permite la vida y la riqueza agrícola del norte peruano; quizás el más fértil y con mayor volumen productivo de todo el espacio centroandino? Ya los Moche (600 d.C.) y consolidados por los Chimús (1200 d. C.), con el agua, crearon canales, ríos y am-

12 Comunicación personal. K.Noack y J. Castañeda han trabajado un proyecto sobre la fundación inicial de la ciudad de Trujillo. En la base de datos, construida por K.Noack, se encuentra la información puerta a puerta de los primeros vecinos de la ciudad y cosas muy interesante, también se encuentra que los caciques cajamarquinos tenían solares en la ciudad. Ver también su trabajo, Noack, 2014.

13 Hagamos un excurso y señalemos pero hoy son un foco problemático en las relaciones sociales merced a la expansión minera, la necesidad de agua de la actividad y sobre todo, de la producción de relaves. El problema mayor es con las Lagunas Conga y la producción de oro de Yanacocha, ver por ejemplo, el resumen sobre el conflicto en http://www.grufides.org/sites/default/files/Documentos/fichas_casos/CONFLICTO\%20MINERO\%20CONGA.pdf . [Recuperado enero 2017] pliaron las tierras de cultivo: potenciaron los valles agrícolamente hablando; convirtieron a toda estas tierras en una suerte de oasis altamente productivos: primero, con maíz y frutales pero luego con caña de azúcar que hasta hoy fundamenta la riqueza agrícola del Perú.

Nos preguntamos si será casual que cuando los incas conquistan a los chimús primero capturan la zona que estudiamos, este eje que va de Huancamba a Loja y fundan Tomebamba. Se dice que como punto de apoyo en la conquista hacia el norte pero quizás como ciudad-control de esta llave del reino; de hecho, la ciudad de Cuenca es un pequeño Cusco ${ }^{14}$. Entre 1463 y 1471 primero se coloca a esta sierra fronteriza, a la Transversal de Huancabamba, y al espacio norandino bajo control inca y luego se enfrenta al poderoso contendor Chimú. Solo se sabe que los Ayabaca y los Bracamoros así como los Paltas y los Cango fueron siempre grupos eminentemente belicosos y que cuando los espańoles llegaron, su manera de insertarse en la problemática realidad local de 1532, fue actuando como ejercito punitivo del curaca Maizavilca: en su subida por la cuenca del CatamayoChira fueron castigados alrededor de 25 señores.

En todo caso, desde Loja a Huancabamba encontramos una suerte de llave del reino: su control permitía asegurar la tranquilidad del espacio centroandino pero también el frenar cualquier intento de acceder o salir del mismo. Podría pensarse que la riqueza agrícola de este espacio norte centroandino debió ser un atractivo para esos grupos clánicos belicosos que provenían originalmente de la selva o de el espacio septentrional andino. Pero también es posible que el sistema hídrico tan particular que se explaya en esta Transversal de Huancabamba tuviese un impacto directo en las condiciones ambientales o en la agricultura; no solo un calendario agrícola sino el control del recurso hídrico del norte del Perú. Por tanto, era interesante e importante controlar esta cabecera tan particular de aguas de superficie y de profundidad. Y de hecho, el control quizás más que militar debió pasar por un control religioso; ¿desde cuándo

14 El primero en afirmar lo dicho es Max Uhle en 1910; ver Uhle, Max; Jorge C. Muelle, David H. Kelley (2008).- "Tres notas sobre la arqueología de Piura».- Lima, Boletín de Lima -- No. 154 p. 5-9. Pero también hay que rescatar las ideas de F.Pease sobre el hecho de que no necesariamente Cusco está referido a una ciudad sino que, al cumplir con determinadas características, se convierte en un espacio sagrado. Comunicaciones de clase, 1988. 
este espacio es sagrado? No debe ser una casualidad la importancia de Nuestra Señora del Cisne, la del Cristo Cautivo de Ayabaca y las lagunas curanderas de Huancabamba y su cercanía geográfica.

Para los locales, cada paso dado en esta transversal debió ser eminentemente sagrado que para una realidad desacralizada como la nuestra es muy difícil de entender: una sagrada llave del reino.

\section{Los espańoles de tierras bajas, los límites audienciales y virreinales}

Con los españoles, llegó un sistema de vida que progresivamente se fue imponiendo, fusionando, mestizando e ínterpenetrando con el que aquí había. Y lentamente fue construyéndose las bases, la infraestructura socio-política para el desarrollo de un tipo de economía de intercambio monetario: la moneda y el mercado de libre negociación fue realmente algo nuevo en sociedades donde la sacralidad de los vínculos pasaba por el intercambio vía parentesco y fundado en dones y contradones. ${ }^{15}$

Si bien los españoles eran personas sumamente religiosas, su perspectiva monoteísta era muy diferente de la local, politeísta y sacralmente presente y activa en todo momento. Los españoles eran fundamentalistas religiosos frente al resto de Europa por haber combatido ocho siglos contra el islam y porque al momento de la conquista, se acababa de limpiar España de árabes y judíos. La violencia que trajeron no era una situación que solo les fuera exclusivamente característico; en las sociedades andinas, tipo Antiguo Mundo ${ }^{16}$, también había un refinado uso de la violencia. Lo que varió fue el rompimiento de los

15 Haciendo un excurso pensemos en cómo contemporáneamente la Iglesia católica con su opción por el pobre y con la teología de la liberación siempre ha mantenido ese vínculo más bien étnico y no solo de pobreza. Solo que en el mundo andino generalmente pobreza y discriminación étnica suelen ir de la mano. Estudios al respecto, pocos. Sobre vínculos religión- indios el clásico es Manuel Marzal (2014) y sobre teología de la liberación, sin ninguna duda, Gustavo Gutierrez Gutiérrez, Gustavo, (2012).- Teología de la liberación: perspectivas, con una nueva introducción mirar lejos.- Lima: Centro de Estudios y Publicaciones, 441 p.

16 Utilizo esta categoría en la línea de algunos textos clásicos en torno a la historia universal que utilizan esta y otras categorías imperios hídricoscuando estudian los reinos egipcios, chinos y de la India. Ver Weber, Alfred (1935).- Historia de la cultura.- México: FCE, 469 p patrones socio-culturales de uso de la misma; ${ }^{17}$ finalmente las prácticas sociales españolas tenían sentido en términos de España y por eso, los recién llegados toman rápidamente las prácticas sociales locales: el primer virrey Blasco Nuñez de Vela se hacía cargar en andas y Alonso de Mercadillo, llegado con Pizarro, murió peleando contra los punaeños (isla de la Puná, frente a Machala, Ecuador) a favor del bando de los tallanes. Pero en todo caso, lo que sí es interesante es que con los españoles llegó una forma de entender la vida donde existían derechos frente al señor; finalmente salían de la baja Edad media peninsular donde los comuneros y condotieros por su condición, lograron tener algunos derechos frente a reyes y señores. En el mundo andino prehispánico, ritualizado y sacro, no habían derechos de ningún tipo frente a los señores, es más, estos eran los únicos que visiblemente tenían espacio en la sociedad ${ }^{18}$.

Por cierto que en la zona de la Transversal de Huancabamba de la que estamos hablando, habían indígenas sumamente belicosos. Además a partir de 1470 aproximadamente se da la violenta expansión inca, por rápida y por guerrera; toda la sierra norandina hasta Quito es conquistado por los incas en alrededor de diez años. Y para consolidar la expansión por la sierra, los incas enfrentan al otro gran imperio andino, los chimús con los que se encontraron militarmente en el norte del Perú, por la costa y por la sierra; finalmente los incas arrasaron Huamachuco, corazón del reino del Chimor o el lugar donde se encontraba una buena parte de la nobleza chimú, a la cual eliminaron. Y a menos de 50 ańos, se da el enfrentamiento entre Huascar y Atahualpa por el incanato y la zona de enfrentamiento fue desde la Transversal de Huancambaba hasta el territorio de los tallanes piu-

17 Es una categoría que se está hoy día revisando en el proceso histórico. Aunque no se refiere al siglo XVI y la conquista, es interesante prestar atención a las nuevas manera de entender la violencia como potenciadora del orden y del cambio. Ver Irurozqui, Marta y Mirian Galante (eds.), (2011).- Sangre de ley: justicia y violencia en la institucionalización del Estado en América Latina, siglo XIX .- Madrid: Polifemo, $364 \mathrm{p}$.

18 De cada uno de estos tópicos, ha muchísimo para pensar. Siempre se plantea una ruptura total cuando llegan los españoles. La tónica de este estudio no es de continuidades y permanencias -como por ejemplo, los franceses con Hocquenghem (1999)- sino como se plantea una vida cotidiana con sociedades establecidas un mínimo de 15000 ańos en estas tierras y la inserción, no solo violenta y problemática sino también pacífica y por asimilación social, de grupos humanos foráneos. Quizás en la línea de K.Noack (2014) que estudia la conquista inca del norte como conquista semejante a la de los españoles. 
ranos y los Cajamarca. Es decir, en nuestro espacio de estudio, tan sagrado, resalta la belicosidad local y con sus enfrentamientos locales (tallanes-ayavacascangos), regionales (chimus-incas) e imperiales (panacas del norte vs panacas del sur incas).

Sin ninguna duda, la consecuencia directa de esta belicosidad y violencia fue el vaciamiento poblacional en el norte peruano. Se sabe que la práctica inca de conquista pasaba por desplazar a numerosos familias completas, los mitimaes, para que, al ser extraño a los locales, se consolidara su presencia política mediante el (re)poblamiento forzado pero leal. No olvidemos que, además, hay que añadir las enfermedades espańoles que causaron más estragos que los españoles en sí pero también las luchas de conquista españolas. Se puede entender por qué Cook señala una caída poblacional de cerca del $90 \%$ en la zona de Piura y del norte del Perú. Comentaba F. Pease que, a la caída del imperio, la mayoría de los grupos mitimaes se regresó a su zona original para no perder sus vínculos de parentesco y por tanto sus derechos y participación política. Estas tierras vacías o con poca gente, fueron un atractivo muy grande para todo un conjunto de desarraigados campesinos españoles que prefirieron asentarse en estas tierras y aindiarse para poder sobrevivir en ellas. ${ }^{19}$

Por tanto, lo primero que salta de la zona en estudio es la complejidad y particularidad social de los grupos allí asentados y mezclados, fusionados e interpenetrados culturalmente que hay que recordar, se han asentado sobre un territorio con formas políticas complejas pero no incas ni mucho menos aún quechuas: son muchik, lengua pescadora, culle y la diversidad de lenguas existentes incluso durante el virreinato. Los recién llegados, los españoles, tienen su propia historia y diferencias pero establecidos en estas tierras, tienen un patrón común y general: son españoles. Quizás de esta buena mezcla no solo de tipos humanos sino sobre todo de perspectivas de vida determinan que la personalidad social de los grupos de este espacio norte-sur de la transversal andina, sean sumamente blancos pero indios y criollos pero ni indios como otros grupos ni tampoco criollos como los

19 El clásico de David Noble Cook, Demographic Collapse. Indian Perú, 1520-1620 (Cambridge: Cambridge University Press, 1982) Algunos apuntes del tema lo trabajo junto con A.Diez en el texto de historia general sobre Piura: Aldana y Diez (1994). Pero no es una idea desarrollada por completo. urbanos y los de la costa. Un espacio serrano que no cumple con los estereotipos sociales: la gente no es india y no se reconocen como parte del mundo inca; son blancos y reconocen influencias virreinales pero se cuestionan el tipo de herencia recibida ${ }^{20}$.

Prácticas indígenas, percepciones españolas. Por ejemplo, la tierra toma importancia en cuanto ella y no por la gente que permite solventar; los límites de las haciendas importaban en cuanto permitía una cantidad de producción agrícola o ganadera, propiedad de un español no de una comunidad. Para los locales andinos, el recurso principal era la gente más que la tierra en sí: la mano de obra era el eje de la explotación y producción comunal; el control de la población era fundamental pero desde una entidad grupal como la comunidad, sometida a los señores. Como muchas sociedades agrícolas, el parentesco era la base del sistema aunque siempre sacralizado y consolidado con la presencia necesaria de un hijo, cuya línea materna era la principal; la complejidad de la construcción de los vínculos y relaciones se ha afirmado múltiples veces por los etnohistoriadores pero son muy difíciles de ser estudiados ${ }^{21}$. Así para los locales, la red-soporte humano de las formas políticas se construía sobre los diferentes grupos humanos; los vínculos entre los caciques y señores era fundamental pues eran los que en realidad eran visibles y respetados. Pero para los españoles el poder se localizaba en un lugar en especial, la ciudad y con un conjunto de autoridades nombrados por el rey o su representante. Por tanto, lo primero que hicieron a lo largo del siglo Xvi fue establecer una rejilla de ciudades que les per-

20 En los años de 1990 se intentó establecer un concurso de belleza regional en la ciudad de Piura. Se señalaba como requisito indispensable, el tener rasgos indios. De inmediato, las ayabaquinas y las huancabambinas se quejaron de la segregación; ellas eran blancas y no podían concursar al título. Hasta ahora se lleva a cabo el famoso concurso ver, "Eligen a la miss Capullana Susy Cunti Cacica» Ver la noticia en www.munitalara.gob.pe. [Recuperado: Martes 20 diciembre 2016]

21 Estoy pensando en los clásicos de Franklin Pease y María Rostowrowski pero en general, el problema de enfrentar sociedades ágrafas cuya memoria se construye y se reconstruye a cada momento. Son además, sociedades que cambian los nombres de los personajes conforme cruzan etapas de vida y que no pierden esa costumbre. Incluso utilizan los nombres indígenas con los indígenas y los espańoles con los españoles. Como el caso de don Francisco Xavier Céspedes y Noriega en pleno siglo XVIII, que solo cuando tiene problemas con sus indios, firma don Francisco Xavier Céspedes y Noriega Amaru Inca Yupanqui. Y buena parte de los notarios de Lambayeque y Chiclayo firman también con un nombre español pero tienen el segundo indígena y lo utilizan con los indios. Es un tema apasionante pero apenas estudiado. 
mitiera el control del territorio a su manera. A diferencia de los locales, la herencia era para el hijo hombre mayor o pariente hombre más cercano y como en España, el privilegio se fundaba en la propiedad de la tierra: para Ramos (1968: 78) el rasgo distintivo de las clases dominantes en la colonia era la propiedad lisa y llana.

Se sabe que Piura fue la primera ciudad; por allí, entraron los espańoles. Y entre 1532 y 1563 se estableció una verdadera rejilla de ciudades. En particular y para el norte del Perú, durante el gobierno de Antonio Hurtado de Mendoza, marqués de Cañete; virrey, dicho sea de paso, que puso en orden a todos los conquistadores que buscaban ser autónomos del rey. Asi Loja fue fundada en 1548 y Cuenca para 1563 pero también Trujillo en 1534 y Santa María de la Parrilla en 1556 en el norte del Perú. No queda claro la opción española por las tierras bajas en el espacio centroandino; en México se establecen en el mismo corazón del imperio azteca ${ }^{22}$ y por su condición minera, en Bolivia también se establecen en plenos Andes. Allí se fundan ciudades importantes como Potosí pero las autoridades viven en la mucho más amable ciudad de Chuquisaca. Pero lo que sí es claro es que en el espacio central andino en lo que hoy es el espacio peruano, la rejilla del poder se establece por la costa mientras que la infraestructura de poder indígena-local se mantiene prácticamente incólume por la sierra. Y sobre todo, progresivamente alejada si alguna vez estuvo cercana- al poder español.

La rejilla de ciudades sostiene una nueva forma de organizar el territorio: las cuencas y su manejo son progresivamente dejadas atrás y se crean virreinos $\mathrm{y}$ audiencias que, a su vez, tienen provincias. El eje que estudiamos, se convierte en una frontera ${ }^{23}$ que, progresivamente, se va alejando y desdibujando en la medida que el límite se establece entre las audiencias de Lima y Quito y de los virreinos de Lima y de Nueva Granada. Lo cual no niega, dicho sea de paso, que sea una región sumamente activa en el tráfago

22 Las posiciones tradicionales señalan que Lima se establece en la costa porque estaba el puerto del Callao y querían tener la seguridad de poder escapar del imperio. Ver cualquier texto clásico de historia del Perú. Como por ejemplo, Del Busto, José Antonio, Ed. (2004).Historia general del Perú.- Lima: Brasa Ediciones, 8v.

23 Como se ha dicho, Turner (1986) es el clásico teórico sobre frontera. Pero notemos que aquí no hay pioneros en continua expansión sobre los indios tribales. Por el contrario, estamos ante un imperio cuya infraestructura de gobierno facilita en mucho, el ordenamiento espańol pero como tantos temas, tiene que ser estudiado. local de productos: en un inicio, el oro es un atractivo formidable pero las dificultades de extracción por límites tecnológicos de época determina lo efímero de la importancia de ciudades como Logrońo de los Caballeros y Zaruma del Oro, todavía en el sur del Ecuador. Conforme se asentaba el gobierno español, que percibía al oro y la plata como la riqueza más importante, esta transversal fue lentamente perdiendo el interés para ambas audiencias, las de Lima y las de Quito. Peor aún, cuando la riqueza agrícola, gracias al azúcar potenció a la costa norte peruana y gracias a la ganadería lanar, los obrajes se asentaron en torno a Quito y región. Y para el gobierno en sí, mucho más interés requería la organización de las actividades mineras en torno al espacio circumlacustre Titicaca o la organización de la economía en torno a CartagenaPanamá y las diversas carreras de comercio.

Porque, lo que si hay que notar es que localmente el tráfago comercial era muy activo. La carrera de valles, es decir, el circuito de comercio que partía de Lima por la costa, empataba la carrera de Quito que se recorría con mulas de reata arriba, es decir, que soportaban la altura de la montañas. Por la costa, en realidad, eran otros animales y recorrían las pampas. Un activo circuito que permitían el constante y continuo intercambio de múltiples productos y que potencia la Transversal de Huancabamba: La Churonita cuenta con un santuario desde 1550 y como con la Virgen de Guadalupe se aparece a los indios para que le construyan la iglesia pero recién en 1594. Mientras que en el caso de Ayabaca, recién para 1751 se construye la iglesia para el Cautivo en una etapa en que los Cristos y las cruces se imponen como representaciones sacras. Con variaciones, las narraciones son siempre semejantes: foráneos que se aparecen y que se ofrecen a trabajar por comida, que se encierran, no comen y luego desaparecen dejando la cruz o la imagen sagrada. ${ }^{24}$

24 Generalmente son dos modelos. En el caso de la Cruz de Motupe, igual es un foráneo que llega hace la pieza y luego desaparece y se dan cuenta de que en realidad eran un ángel. Cuando se trata de imagen en bulto, como la Virgen de Guadalupe en el norte del Perú traída desde Espańa, el milagro reside en que no se quiere ir de la zona y cada vez que se la quieren llevar, desaparece y aparece misteriosamente en su iglesia. Sobre la Cruz de Motupe hay múltiples historias que son vendidas y repartidas en la localidad; en la web, ver http://www.lambayeque.net/lambayeque/motupe/ [recuperado enero 2017]. Sobre Guadalupe, hay todo un informe de investigación no publicado; una pequeńa parte en «Entre obreros del Seńor: Conflicto y competencia por el control del Santuario de Nuestra Seńora de 
No es casual que en las colonias se construyeran 70.000 iglesias y 500 conventos con más de 3.000 religiosos, como afirma Ramos (1968). La religión supuso un ordenamiento que permitió que se montaran las percepciones de vida española sobre las prácticas indígenas. Los jesuitas desarrollaban prácticas que se centraban en el éxito futuro más que en la realidad presente; la conversión para ellos, es siempre una cuestión de tiempo a causa de un proselitismo adecuado, sistemático y ordenado como todo aquello que se asuma como parte de la modernidad y como orden servían de brazo burocrático de la corona en espacios de difícil acceso como la selva; Jaén de Bracamoros y en general toda la zona virreinal de Maynas (cuyo acceso, dicho sea de paso parte de la transversal de Huancabamba que estudiamos). Una suerte de orden especializada en las marcas o zonas de fronteras que se completaban antagónicamente con los dominicos, los guardianes de la fe, fundados en la fe como razón natural, establecía una normativa, exigente en su práctica y cuidadosamente vigilada. Ambos dos estuvieron siempre presentes desde la infraestructura de poder; los de a pie fueron justamente las órdenes que trabajaron directamente con los indígenas: en el norte, los franciscanos estuvieron siempre en zonas con densidad indígena como Chiclayo y también fueron importante los mercedarios, todos los cuales se complementaban con los curas diocesanos. En realidad, poco se ha estudiado la importancia del impacto del poder religioso en tierras tan sagradas que, más que probablemente, tuvieron mayor éxito que el militar ${ }^{25}$.

Vaciamiento poblacional, violencia de uso constante, uso del pensamiento y prácticas sacras, gente india y española fusionada, interpenetrada, y mestizadas que marcaron la personalidad histórica del eje que

Guadalupe» en Revista Histórica.- Lima, Vol XXX, No. 2, Dic. 2006, pp. 41-68.

25 Con respecto a los jesuitas y su accionar en la etapa temprana de la conquista, ver la tesis de por ejemplo, Dejo Bendezú, Juan Miguel.La mistica de la acción de los primeros jesuitas en el Perú: introducción a una historia de la espiritualidad colonial.- Lima, PUCP, 2008 (Ts). Por supuesto, clásicos los trabajos de Manuel Marzal, Sj., fundador del Instituto de Pastoral Andina; ver por ejemplo, el libro que coedita con Sandra Negro, Un reino en la frontera. Las misiones jesuitas en la América colonial.- Lima: PUCP, Abya-Yala, 2000. Desde otra perspectiva muy diferentes y en términos del Perú, están los estudios de Juan Carlos Estenssoro (Del Paganismo a la Santidad. La incorporación de los indios del Perú al catolicismo 1532-1750.- Lima: IFEA, 1998) y Gabriela Ramos (Muerte y conversión en los Andes, Lima y Cuzco, 1532-1670. Lima: IEP; IFEA 2010). nos interesa. El virreinato de Nuevas Castilla se crea en 1542 y poco después, en 1545, la Real Audiencia de Lima; y de ambas organizaciones dependen el resto de las audiencias con excepción de Venezuela y ciertamente Brasil. La audiencia de Quito se crea en 1563 y gracias al documento de su creación sabemos que, «tenga por distrito la Provincia de Quito y por la costa azia la parte de la ciudad de los Reyes hasta el puerto de Payta exclusive y por la tierra adentro, hasta Piura, Caxamarca, Chachapoyas, Moyobamba y Motilones, exclusive, incluyendo azia la parte susodicha los pueblos de Jaén, Valladolid, Loja, Zamora, Cuenca, La Zarca y Guayaquil con todos los demás pueblos que estuvieran en su comarcas». Esta real cédula sirve de base a la Ley X de la Recopilación de Leyes de Indias de 1680 en donde queda oficialmente reconocida esta audiencia ${ }^{26}$.

De lo dicho, se ve que los españoles respetan la transversal de Huancabamba como zona de frontera entre los Andes septentrionales y los centrales, entre las audiencias de Lima y Quito. Del lado de Piura, quedan los Ayabaca, los Huancabamba y los Bracamoros, como era al momento de la llegada de los españoles, y del otro lado, vinculado a Loja quedan todos los grupos propiamente jíbaros. A pesar de que humanamente estas tierras están poco pobladas, tanta exactitud y conocimiento implica que los recién llegados respetaron inicialmente el ordenamiento existente; sólo en el tiempo las cosas irían cambiando y radicalmente. Como hemos visto, las ciudades serían los caballos de Troya de los conquistadores: la distancia de la rejilla de las ciudades más importantes, las dificultades geográficas signa un relegamiento que llegara prácticamente al olvido pero por otro lado, potencia a los señores y su presencia más que relativamente autónoma con respecto a sendos gobiernos (virreinato y audiencias de Lima y Quito). El límite se establece en el papel; se le contempla alejadamente aunque la frontera está viva y sumamente activa como paso obligado de la carrera de valles hacia Cuenca y más allá.

26 La creación de la Audiencia de Quito es un tópico nacional central para la historia del Ecuador; es muy fácil encontrar la referencia a esta fundación. Desde wikipedia hasta trabajos formales de historia como Enrique Ayala Mora, Ed.- Documentos de la historia del Ecuador.Quito: Corporación Editora Nacional, 1995. Y en general, revisar toda esta serie, Nueva Historia del Ecuador; los volúmenes 3, 4 y 5 corresponden al período colonial. 
Valga recordar que con el nuevo ordenamiento español, es visible que hay una pugna entre los imperios para ver quien cuenta con el respaldo de este nuevo poder. Lima es una ciudad que está en la frontera sur del imperio chimú y como demuestra el estudio en curso de T. Vergara ${ }^{27}$, la presencia y poderío de los indios norteños es totalmente visible en los tempranos años virreinales. Pero la opción de los virreyes desde Andrés Hurtado de Mendoza, marqués de Cañete (1556-1560) es por los herederos del imperio inca; cuando este virrey teje una alianza con Sayri Tupac (1558) dándole la rica encomienda de Yucay, dispara toda una suerte de descontentos en todo el norte desde los espańoles pero sobre todo desde los indios; rechazos que llegan hasta la frontera que estudiamos y la cruzan: una consecuencia directa de estos eventos es la fundación de la ciudad de Cuenca en 1563. Se sabe que en la zona hacía mucho que habían asentados españoles pero no se contaba con una ciudad. El virrey envía directamente un plenipotenciario con la orden de convocar a los cuatro principales indígenas de la zona para concertar la fundación de la ciudad y Cuenca se funda no sobre la ciudad prehispánica de Tomebamba sino en los linderos de ella, como en varios otros casos del norte peruano (Chanchan y Trujillo). Y poco tiempo después, con el virrey Toledo hubo una suerte de negociación: los señores de la sierra central presentaron su propuesta de cómo querían ser gobernados. ${ }^{28}$

Mucho tiene que ser repensado; por cierto que la organización hispánica se fue dando de a pocos en el tiempo. El interés del virrey es hacia el sur y entreteje el destino del reino con los incas cuyo poder sobre el altiplano es visible: el formateo sociopolítico del imperio facilita el accionar de la corona española. Es decir, en las zonas pacificadas por el imperio o bajo su control directo es más fácil la imposición del or-

27 La Dra.Teresa Vergara es una reconocida especialista del tema indígena. Su interés actual académico actual está centrado en los indios de Lima y la construcción que hacen de la Nación Yndica en el siglo XVIII aunque para ello, perfila su accionar desde el siglo XVI.

28 Quizás el único que ha publicado algo sobre los acuerdos indígenas coloniales es Javier Tantaleán Arbulú.- El virrey Francisco de Toledo y su tiempo: proyecto de gobernabilidad, el imperio hispano, la plata peruana en la economía del mundo y el mercado colonial (Lima: Universidad San Martín de Porras, 2011). Allí se publica un documento con la propuesta de varios cientos de curacas de la zona central peruana que, bajo la dirección del dominico Fray Domingo de Santo Tomas, buscaban un acuerdo de gobernabilidad con la Corona espańola que no con los conquistadores o beneméritos. den español y la extracción del oro y sobre todo de la plata; probablemente la negociación no se limita a lo económico no por puro gusto el virrey marqués de Cañete ofrece a Sayri Tupac su palacio virreinal que es rechazado en favor del palacio arzobispal ${ }^{29}$. Los del norte son dejados de lado a pesar de su poder agrícola; solo mucho después, en el siglo XviII, la administración española se volcaría hacia esta zona en busca de la ampliación del cobro de impuestos al comercio y al azúcar aunque con muy poco éxito. Es en esta etapa, segunda mitad del siglo Xvi, cuando el marqués de Cańete y el virrey Toledo sancionan la opción definitiva de España por el mundo oficial andino, es decir, se entretejen los intereses de la corona espańola y la corona inca.

El espacio entre Loja y Piura, con proyecciones hacia Cajamarca, Jaén y Chachapoyas, deja de ser el espacio eminentemente belicoso que era $y$, por el contrario, progresivamente es invisibilizado y prácticamente olvidado. En la transversal de Huancabamba se encuentran indios y españoles que viven un cotidiano aindiado; la curandería es un sistema médico pero sagrado y mágico: se bautizan las prácticas y se mezclan, además, con lo esotérico español; incluso se dice que allí llegaron grupos perseguidos de judíos y judaizantes $^{30}$. Un espacio sagrado que amplía su sacralidad para incorporar a los recién llegados y que se invisibiliza prácticamente hasta el siglo Xx. Con algunas excepciones, como con la explotación de la quinina.

\section{La construcción de una vocación exportadora, la construcción de fronteras}

En el caso de España, las llaves del reino fueron puntos estratégicos que impidieron la presencia no deseada de piratas y otros comerciantes encubiertos. La

29 Algo he trabajado del tema en Cañete, ver Aldana (2008)

30 Es interesante lo poco que se puede encontrar en los archivos sobre las zonas de sierra piuranas. Localmente, las particularidades de esta zona son explicadas a partir de la presencia de judíos, como Paladines en Loja, un trabajo bastante sólido. Conversación personal con Sr.J. Paladines, octubre 2016; ver el texto de Ricardo Ordoñez Chiriboga (2010 ).- La herencia sefardita en la provincia de Loja.- (Recuperado: http://www.esefarad.com/?p=14284). Incluso hay quienes dicen que las características y los elementos sagrados del Cristo Cautivo en Ayabaca reflejan a los Templarios; poderoso grupo de sacerdotes guerreros que brutalmente perseguidos en el siglo XIII habrían sobrevivido escondidos en España y que habría pasado a Hispanoamerica. Lo interesante en todo caso es que los locales se dan cuenta de su particularidad y buscan como explicarse. 
mayoría se ubicaron fundamentalmente en el Caribe pero el Río de la Plata y Chiloé también estaban dentro de las llaves a cuidar. Como dice Zapatero (1946), se trataba de proteger América de los intereses de imperios y reinos europeos; en ese momento la riqueza estaba en el sur y luego entre México y Bolivia.

Porque, como se sabe, conforme se desenvolvía el virreinato, el interés de la Corona española por sus colonias se centró en la explotación del oro y la plata; mantener un imperio requería de una gran producción y de una solvente economía y España llevó adelante prácticas bullionistas y mercantilistas, como era lo normal en la época, para solventar múltiples guerras que sostuvieran el poder de su imperio. Las zonas de sierra, con poca o ninguna producción de estos metales en esos momentos, fueron progresivamente dejadas de lado y en particular, la lejana, distante y de difícil acceso frontera norte de la audiencia de Lima. Por tanto, nuestra frontera en estudio quedó progresivamente relegada: su condición de llave del reino estuvo enmarcada en otro tipo de interés imperial (prehispánico) pero también de creencias. El interés administrativo del virreino estuvo centrado en el oro y la plata extraída en grandes volúmenes desde el surandino y si del Ecuador se trata, la riqueza eran las grandes manadas de ganado ovino y la producción obrajera; poco o nada importaba el sur de la audiencia.

Pero también es posible pensar que a la gente de este espacio le interesara mantenerse invisibilizada. Por su misma condición de poderoso corazón mágico y sagrado curanderil y el espacio para judíos y judaizantes o para cristianos nuevos, es posible pensar que a los locales, nastivos y foráneos, no les interesaba ser encontrados. Incluso podría verse hasta una suerte de conveniente olvido si pensamos en cómo se requerían de órdenes, como los jesuitas, que se encargaban de controlar e incorporar a la burocracia del virreino los espacios difíciles, como para estos jesuitas era la selva: Maynas y el Marañón y luego Amazonas eran el paso obligado al Brasil portugués. Más que un enfrentamiento frontal con los locales - que no era su estilo y que sabían que iban a perder a todas luces - simplemente les interesó lanzar al olvido el lugar y sus prácticas. Pero habría que estudiarlo.

Finalmente los curanderos, médicos andinos, se ganaron el reconocimiento oculto de las esferas de poder con su práctica. Como con el caso de la virrei- na marquesa de Chinchón que en 1633 enferma de malaria, sin posibilidad de ser curada por los médicos españoles, supuestamente fue curada por un jesuita que había aprendido de los nativos el uso de esta yerbas; una versión alternativa señala que fue directamente un curandero. En todo caso, se sabe que hasta la república la gente prefería curarse con un médico indígena que español y sobre todo desde el siglo XVIII, bajo las fuerzas de la Ilustración, comienza a reconocerse todo lo americano agrícolamente utilizable. ${ }^{31}$

Ahora bien, olvidado de la mano virreinal, el eje de Huancabamba se reconstruye conforme lo hace todo el espacio que va desde las zonas de sierra del sur de la audiencia de Quito hasta las tierras del norte de la de Lima. ¿Se trata del espacio que otrora estuviera bajo la influencia y la impronta del reino del Chimor? En todo caso, la experiencia virreinal española le añadió la ciudad de Guayaquil y su interland así como el puerto de Paita y las relaciones mercantiles constantes y continuas por mar en torno al mercado de intercambio. Una región que reconstituida a lo largo del siglo XVII, emerge poderosa en el siglo XVIII merced al constante intercambio y mercadeo de productos agrícolas, ganaderos y de pesca, que potencian una cantidad de vínculos humanos que se proyectan sobre un espacio geográfico dado, el sur del actual Ecuador y el norte del Perú, pero que los rebasa por completo: por mar, se inserta en la realidad del mar Pacífico y a través de Panamá, en el tráfago del Caribe; por tierra, en todo el espacio virreinal peruano. Un espacio bastante autónomo del poder central donde los señores llegan a tener gran fuerza económica y presencia política gracias a su riqueza y en la que los señores indígenas y algunas comunidades indígenas tienen su espacio socio-político totalmente establecido aunque tácitamente aceptado y oficialmente invisibilizado. El comercio y el intercambio son el sustento económico de esta región humanamente construida.

Para el siglo XviII y bastante de golpe para la región en sí, las relaciones internas tienen que cambiar: la dinastía de los reyes es otra y con ello, su percepción de cómo debe realizarse el ahora si coloniaje;

31 Sobre la quina los estudios más importantes están hechos desde el Ecuador, como por ejemplo el de A.Moya (1994). Y sobre el Obispo Martínez de Companón el estudio más reconocidos es el de Restrepo Manrique, Daniel (1992).- La Iglesia de Trujillo (Perú) bajo el episcopado de Baltasar Jaime Martínez Compañón, 1780-1790.- VitoriaGasteiz: [Gobierno Vasco], 2v. 
atrás queda la experiencia indiana y ahora si se ejerce el dominio colonial. De pronto, la Corona tiene interés en cobrar impuesto de todo lo cobrable; es decir, el gobierno real busca modernizarse y se interesa no solo en el oro y la plata sino en general en el tráfico económico de los productos agrícolas, aquellos que en términos contemporáneos llamaríamos recursos naturales. La macrorregión - de la que el eje LojaHuancabamba es solo una parte- consolida cada vez más su poder y comienza lentamente a expandirse sobre la política del reino. ${ }^{32}$ Los cambios están signados no solo por políticas que favorecen a la metrópoli sino también porque aparecen agentes externos que buscan insertarse en la región o utilizar los recursos de la región; sobre todo aquellos con alto retorno como la quinina. Los señores, criollos o caciques, tenían sus haciendas, sus industrias y sus comercios; formas privadas de propiedad que serían sometidas a otro tipo de tensiones con el cambio de los tiempos pero no una competencia directa como con la producción de la quinina a lo largo y ancho de la serranía norteña y en la Transversal de Huancabamba.

Como se ha mencionado, España conoce la quinina y sus propiedades febrífugas gracias a la enfermedad de la virreina Ana de Borja, marquesa de Chinchón. Desde ese momento, la Botica Real de Madrid comienza una fuerte demanda de este producto: era no solo muy solicitado sino además altamente buscado; en una sociedad tan guerrera como la española tratando de mantener la importancia de su imperio, la muerte entre la soldadesca por fiebres era lo común. Por tanto, conforme se conocía las propiedades de este producto, la demanda fue en aumento. Había que sacarla de las profundidades de la sierra, sobre todo de la lojana pero también había «manchas» o bosquecillos de cascarilla por Huancabamba y Ayabaca. Pero las más reconocidas eran las de los montes Uritusinga en Loja por "prietas y coloradas». Esta corteza era arrancada de los árboles, cuidadosamente preparada, empetacada y transportada por los indios; el camino al mercado final era largo y si no estaba bien acondicionada, la cascarilla perdía fuerza,

32 Por ejemplo, C.Mazzeo trabajó a un importante comerciante trujillano, Lavalle, que termina siendo la cabeza del Tribunal del consulado en Lima y con ello, de los destinos del comercio virreinal. El interés de la autora, sin embargo, no fue se centró en la región. Ver Mazzeo, Cristina Ana (1994).- «El comercio libre en el Perú: las estrategias de un comerciante criollo: José Antonio de Lavalle y Cortés, Conde de Premio Real, 1777-1815.- Lima: PUCP, 279 p. se malograba y no servía para nada. Los sacerdotes locales solían ser los encargados de organizar la explotación y el envío a los acopiadores; eran los intermediarios entre los comunes de indios y los comerciantes y muchas veces también participaban económicamente en el intercambio. Ellos también defenderían la propiedad y explotación de la quinina por parte de los indios.

Por su parte, los comerciantes, criollos por lo común, eran grandes negociantes en las diferentes carreras de comercio del virreino y del imperio y llegaban al mercado madrileño. Personajes como el lojano don Pedro Javier de Valdivieso o don Joséf de la Carrera pero también el piurano Gregorio Espinoza de los Monteros eran bastante reconocidos en el norte por el conjunto y el volumen de productos que comerciaba para con España ${ }^{33}$. Ellos acopiaban el producto en alguna ciudad, Cajamarca o sobre todo Trujillo y la enviaban por mar hacia Panamá o Cartagena para que finalmente, fuera reembarcada hacia Espańa y la Botica Real de Madrid. Moya (1994) señala que también se exportaba por Guayaquil pero las condiciones de envío era mucho más difícil por el bosque tropical que por las pampas costeras del norte de la audiencia de Lima.

La demanda de quinina se disparó hacia la década de 1760; prácticamente se depredaron los bosques de quinina en Loja y de manera apremiante, se comenzaron a buscar cada vez más «manchas» o bosquecillos del árbol: la Botica Real monopolizó la producción de quinina para evitar su desaparición. Mientras que en 1782, la arroba se pagaba entre 8 y 19 ps puesta en el sitio, para 1790, ya no se encontraba el producto en Huancabamba ${ }^{34}$. Algunas «manchas" de este árbol se encontraron en Cuenca pero también se hallaron y hasta se sembraron en la zona Huánuco, en el centro, y en la zona de Cusco; ambas zonas de ceja de selva peruana.

Los acopiadores comenzaron a sufrir la competencia de comerciantes, vinculados al subdelegado,

33 Ver Archivo Regional de Piura (ARP), Cabildo Leg.11, exp.204, 1809. Una presentación general del comercio general de la zona y la actividad de los mencionados en Aldana, 1999

34 Hay pocos estudios sobre la quina para el caso del Perú pero muchos para el Ecuador. Ver por ejemplo el muy completo estudio de Moya (1994). Por otro lado, la información recogida de Humboldt está en sus notas; las publica Vegas Vélez, Manuel (1991).- Humboldt en el Perú. Diario de Alejandro de Humboldt durante su permanencia en el Perú.- Piura: CIPCA) 
que contrataban a su propia gente - negros costeños por ejemplo- para dedicarse a la explotación de la cascarilla sin tener que pasar por el Común ni por el sacerdote ni tan siquiera para conseguir la mano de obra: un ejemplo. Eran españoles que contaban con el apoyo oficial y ello les permitía imponer condiciones distintas de negociación: los indios de Chillaos, en Bagua, señalaban

[...] obramos consultando la paz y tranquilidad de nuestra republica que VM la tiene desavenida, conquista por el ridículo motivo de sus fines particulares en la negociación de cascarilla pretendiendo hacerse de ella fuera de la orden legitima que debe guardarse en los pueblos de indios como lo es este a quienes pertenecen los montes de donde las ha estado VM mandando sacar subrepticiamente $[\ldots]^{35}$

Los comerciantes, como el Capitán don Julián de la Vega y Cáceres, se quejaba ante las autoridades locales y regionales (Trujillo del Perú) que no podía extraer la quinina por «la general propensión de los indios de esta provincia al ocio y araganería». Desde Chachapoyas, semejante a Cuenca en cuanto cierre geográfico-humano de la trasnversal de Huancabamba, la defensa de los derechos de los foráneos pasaba por sustentar y demostrar la barbarie y poca civilización de los indios. De poco o nada servía, como en el caso de los pueblos de Olleros, Diosan, Jambajalca y Quinjalca hacia la zona de Cajamarca, que se quejaran que los foráneos no cumplían las normas locales; por ejemplo, querían pagar los $2 \mathrm{r}$ y no los 4r establecidos. Muy cerca de allí, tenían el mismo problema: Dn Manuel Miguel de Sans, juez real subdelegado, tiene permitido a Don Francisco de la Lama, la extracción de cascarilla y si el Común no lo permite pues le impone una multa de 200ps. ${ }^{36}$

Para este momento, inicios del siglo xIx, solo importa quien tiene la propiedad y el derecho de explotación; anteriormente, cada quien tenía su espacio de participación. Mientras que los indios eran los que cortaban la corteza, los sacerdotes se encargaban de

35 Ver Archivo Regional de Trujillo (ART), Intendencia, leg.412 exp. 2460,1806

36 Ver ART, Trujillo Intendencia ley 407 exp 2275, 1786. Recordemos que en Loja y particularmente en Huancabamba, la sobreproducción prácticamente había eliminado la quinina de la zona para 1780. También utilizamos el expediente ya mencionado ART, Intendencia, leg.412 exp.2460, 1806. la negociación y los comerciantes de su colocación final. En los dos casos que presentamos, los foráneos no lograron imponerse a los indios sino por el contrario los Comunes lograron mantener el control de la producción y traslado a mercados intermedios; los españoles, foráneos y con el aval lejano del subdelegado, no pudieron imponer su voluntad de controlar la producción y comercialización de la quinina. Pero se comenzaba a construir un mercado donde la oferta y la demanda se convertían en elemento fundamental; reglas económicas que se explayarían en la subsiguiente sociedad liberal bajo las formas capitalistas, exclusivas y excluyentes, que generaban una frontera diferente, geográfica pero también mental-humana.

\section{Reflexiones finales}

A veces, lento pero en ocasiones muy rápidamente, el producto de la tierra deja de serlo y se convierte progresivamente en materia prima. El problema es que no todos ni todo se mide por economía y es más que probable que la sociedad andina prehispánica se moviera más en términos sagrados que económicos. Situación que supondría una relectura de la historia por cuanto el eje de vida, organizador y articular social, es sin duda alguna lo sagrado. Quizás menos como religión y si más como creencia; poco o nada se ha reflexionado al respecto. En el rompimiento hoy del sistema que se inició a fines del siglo XviII, emergen y reemergen posiciones y reinvenciones sociales del concepto sacro aunque cristianizado bajo la advocación de Vírgenes (Cisne y Mercedes) y Cautivo así como el poder sacro de las lagunas, las Huaringas. En un espacio-llave del reino tiene sentido pensar que se buscaba proteger la «riqueza» hídrica de las altas punas (vir-cocha) de lo que se deriva todo lo demás, economía, política y sociedad. Sin embargo, es solo un planteamiento teórico, muchísimo tendría que ser estudiado para poder aceptarlo como cierto.

En todo caso y bajo análisis más tradicionales, se puede afirmar que hay una conversión del territorio sagrado en territorio económico. La llave del reino se convierte en una frontera, alejada, en la que ya a fines del siglo XviII es posible percibir formas bastante capitalistas que potencia el tránsito de lo local y lo regional al plano virreinal tardío y luego nacional. Si el límite fue importante para marcar la diferencia 
del espacio de control de la audiencia de Lima y la de Quito, aquí dicha importancia comienza a teñirse de matices muy distintos: se busca separar fronteras que no son solo un rango de terreno donde vive gente sino tierras cuya riqueza comienza a ser buscada para sustentar más que el virreinato, la república inicial. Si bien en un inicio, las repúblicas tendrán problemas para constituirse políticamente hablando, el tema de las fronteras irá tomando cada vez más importancia de la mano con la constitución y consolidación del Estado-nación y la creación de un mercado nacional cuya riqueza depende del territorio que comprende.

Por tanto, el territorio es quizás el capital más seguro con que cuenta la empresa, llamada país, que se quiere montar. A más territorio, más riqueza; definitivamente quedan atrás los espacios-clave de control de territorio, aquellas llaves del reino que, como en el caso que estudiamos, separaban los Andes septentrionales de los centrales y protegían la rica sociedad agrícola del centro. Tan poco los límites virreinales fueron útiles para la construcción republicana; los límites heredados eran medianamente indefinidos porque respondían a las características de la etapa previa: el virreinato era parte del imperio español así se pudieran reconocer particularidades como la macroregión surquiteńa-norlimeña, es decir, el conjunto sistémico de regiones que se explayaba entre el sur de la audiencia de Quito y el norte de la de Lima y que incluía a la Transversal de Huancabamba.

El juego cambia y en la medida que el capitalismo se fue imponiendo mientras se comenzaba a generar la república y el Estado-nación, el capital nacional e internacional fue desplazando al poseedor del capital local y hasta regional; el sueño, imposible por lo demás, es la industrialización. Si los productos de la tierra fueron explotados conjuntamente por el Común de indios, el sacerdote y los comerciantes en este eje Loja-Huancabamba donde durante todo el virreinato, a las finales el ahora aviador-prestamista- inversionista con vínculos políticos foráneos a la localidad y también a la región, comenzará a imponerse, como será tan usual durante la república. Aunque no tan anhelados como el oro, la plata y el cobre del sur, el comercio local de productos agro-ganaderos dejaban interesantes retornos que propiciaron el intento de construir verdaderos muros intangibles que, cual paredes, dividieran el espacio entre dos naciones - Perú y Ecuador-; los límites se vuelven republicanos.
Pero la lejanía juega a favor de la región. Los comerciantes, los arrieros y hasta los bandoleros se mueven constante y continuamente en esta esta frontera imposible de diluir; los límites responden a la nación y a veces, se perciben en la región pero si bien son conocidos por los locales, no suele significarles mucho. Socialmente la transversal de Huancabamba como toda la antigua gran región, cuenta con grupos humanos muy mestizados, indios blancos, criollos rurales no urbanos, que construyen rápidamente sus barreras culturales además de su frontera local. Una frontera fuerte y viva incluso hasta hoy día donde se entretejen un conjunto de relaciones socio-económicas que vinculan diferentes actores sociales y articulándolos en diferentes niveles a lo largo y ancho de este territorio; un punto central, recogen lo sagrado como visión eje de vida.

El límite republicano fundamenta una frontera establecida desde siempre: flexible a diferentes culturas, porosa a las distintas prácticas de vida y permeable a los intereses locales, regionales y nacionales. El eje entre Loja y Huancabamba, entre el sur del Ecuador y el norte del Perú, restructura una realidad que se hunde en la noche de los tiempos.

\section{Bibliografía}

Aldana Rivera, Susana (2016). «A caballo entre naciones, la macro-región surecuatoriana y norperuana» en: Municipio de Loja. Loja Histórica. Loja: Municipio de Loja. pp. 44-61.

Aldana Rivera, Susana (2014). "La vigencia del Mundo andino: la larga trayectoria desde el Prehispánico a nuestros días» [revisado] En: Apostilla. Revista Crítica de Lecturas Históricas. Lima, 1(1).

Aldana Rivera, Susana (2008). «Nación antes que región. La construcción del estado nacional y su impacto en la región surecuatoriana-norperuana» En: Ciudad y Arquitectura. Lima, (1) . pp. 129-148

Aldana Rivera, Susana (2008). "La villa de Cañete, para la conquista del reino» en: Revista Andes. Antropología e Historia. Salta (Argentina), (19). pp.183-210.

Aldana, Susana y Alejandro Diez (1994). Balsillas, piajenos y algodón. Procesos históricos en Piura y Tumbes. Piura: Cipca.

Betancourt Mendieta, Alexander y José Gudalupe Rivera Gonzáles Eds. (2015). Territorios y fronteras: 
miradas desde las Ciencias Sociales y las Humanidades. Barcelona; México, Anthropos Editorial; Universidad de San Luis Potosí.

Del Busto, José Antonio, Ed. (2004). Historia general del Perú. Lima: Brasa Ediciones, 8v.

Guffroy, Jean (1986). «Implantaciones humanas y ocupación del espacio en la provincia de Loja durante la época prehispánica» En: Actas del coloquio "Ecuador 1986». Cultura. Revista del Banco Central del Ecuador, 8 (24b), p.579-591. (Recuperada: http://www.documentation.ird. fr/hor/fdi:26534)

Guffroy, Jean; Kaulicke, Peter y Krzysztof Makowski (1989). "La Prehistoria del departamento de Piura: estado de los conocimientos y problemática» En: Bulletin de l'Institut Francais d'Etudes Andines. No. 2, pp.117-142

Hocquenghem, Anne Marie y Zaida Lanning, Eds. (1999). "Contribución al conocimiento de una zona de encuentro entre los andes ecuatorianos y peruanos.Lima: CNRS; IFEA; IRD, 76 pp.

Hocquenghem, Anne Marie (1991). «Frontera entre áreas culturales nor y centroandinas en los valles y la costa del extremo norte peruano" En: Bulletin de l'Institut Francais d'Etudes Andines. Vol.20(2): 309-348.

Marzal, Manuel; Romero, Catalina y José Sánchez, Ed. (2004). Para entender la religión en el Perú. Lima: PUCP, 529 pp.
Moya Torres, Alba (1994). Auge y crisis de la cascarilla en la audiencia de Quito, siglo XVIII. Quito, Flacso, 251 pp.

NoAcK, Karoline (2014). «El legado del imperio Chimú conquistado por los Incas ante la colonialidad del imperio español» En: Tercer Congreso Bienal de la Asociación Internacional de Estudios Interamericanos. Coloquio: De/Colonización en las Américas. Cambios y continuidades. Panel: Argouse, Aude y Karoline Noack. Reiteración de la colonialidad a lo largo de la historia y de la historiografía: lógicas imperiales y lógicas coloniales. Lima: PUCP, 6 al 8 de agosto.

Pease G. Y., Franklin (2001). Del Tahuantinsuyo a la historia del Perú. Lima: PUCP, 390 pp.

Ramos, Jorge Abelardo (1968). Historia de la nación latinoamericana. A. Peña Lillo.

Rostworowski de Diez Canseco, María (2014). Obras completas. Lima: IEP, $8 \mathrm{v}$.

TURNER, Frederick Jackson (1986). La frontera en la historia americana. San José: Universidad Autónoma de Centro América, 401 pp.

Zapatero, Juan Manuel (1964). La guerra del Caribe en el siglo XVIII. San Juan de Puerto Rico: Instituto de Cultura Puertorriqueña. 